\title{
Trans-identity in Benin: Fact or Fiction? Social Response and Consequences
}

\author{
Septime Hessou ${ }^{1,2}$, Yolaine Glèlè Ahanhanzo ${ }^{3, *}$, Alphonse Kpozèhouen ${ }^{3}$, Tranquilin Yadouleton ${ }^{1}$, Odile \\ Sodoloufo ${ }^{1}$, Virgile Capo-chichi ${ }^{4}$, Bruno Doussoh ${ }^{4}$, Bernard Gnahoui-David ${ }^{5}$, Alphonse Biaou ${ }^{6}$, \\ Colette Azandjèmè ${ }^{7}$
}

\author{
${ }^{1}$ Plan International Benin, Benin \\ ${ }^{2}$ Interfaculty Centre for Training and Research in Environment for Sustainable Development, Benin \\ ${ }^{3}$ Department of Epidemiology and Biostatistics, Public Health Regional Institute, Benin \\ ${ }^{4}$ Leadership and Development Consulting, Benin \\ ${ }^{5}$ Plan Canada, Canada \\ ${ }^{6}$ National Program against Buruli Ulcer, Benin \\ ${ }^{7}$ Department of Health Promotion, Regional Institute of Public Health, Democratic Republic of the Congo
}

Copyright $\odot 2019$ by authors, all rights reserved. Authors agree that this article remains permanently open access under the terms of the Creative Commons Attribution License 4.0 International License

\begin{abstract}
Transgender individuals are recognized globally as a key population that is at heightened risk than the general population for transmitting and contracting sexually transmitted infections (STIs) and human immunodeficiency virus (HIV). One of the social outcomes of the gender transition process is the adoption of risky behaviours as coping strategies. Examining the unique health-related needs of transgender individuals in Benin, this study describes the experience of being transgender, along with the social and community ramifications associated with this identity. The research team conducted a cross-sectional study in 2017. Study participants were recruited via respondent-driven sampling among networks across Benin. Inclusion criteria included self-identifying as transgender and being over 15 years of age. Data were collected via questionnaires regarding individuals' management of the gender transition, reactions within their community and social spheres, and engagement in risky behaviours. A total of 326 transgender individuals were identified with a majority of participants being born biologically male (89.57\%). The average age was $24.13 \pm 4.88$, with a strong representation of students (36.50\%). In $64.72 \%$ of cases, participants' families were informed of their transgender identity. The overall attitude of families was of acceptance/support in 7 cases out of 10 . Stigmatization and discrimination were reported by $50 \%$ of the subjects and $59.02 \%$ were subjected to at least one assault. Among these, half were unable to pursue legal action in response, with the main reason being a lack of knowledge of their options for legal recourse. Having multiple sexual partners was the most common risky behaviour among participants, occurring in $81.54 \%$ of the cases. Transgender individuals constitute a population with
\end{abstract}

specific needs in Benin. The services and interventions dedicated to this population must integrate the prevention of STIs and HIV, along with providing legal, social and psychological support.

Keywords Transgender Persons, Social Stigma, Benin

\section{Introduction}

Transgender individuals are those whose gender expression (via their appearance, lifestyle, or other manifestations of their gender) differs from that of the sex they were assigned at birth. Transgender individuals may modify their assigned sexual identity in various ways, ranging from behavioral and clothing changes to gender reassignment surgery. These groups are recognized as having specific health needs, particularly around mental and emotional health, due to the stress associated with the gender and identity transition. The psychological toll that transgender individuals face during their transition is particularly high for those living in communities or contexts that are ill-prepared or unfamiliar with the identity changes and changes of thought that occur among transgender individuals [1-3]. In such settings, transgender individuals may be targets of discrimination and stigma, making them particularly vulnerable and at risk of adopting behaviors such as alcohol and substance use or risky sexual behavior $[4,5]$. Transgender individuals are thus a key population at high risk of contraction and/or transmission of STIs and HIV [6, 7]. 
There is a lack of research in the literature on transgender populations in Africa, for a variety of reasons. This marks an important research gap that needs to be addressed, in order to identify effective intervention strategies that address the unique health needs of transgender populations and that reduce the potential for risky behaviours (including those that lead to increased risk of HIV and other diseases) [7-9]. Several authors agree on the importance of parental and family support, along with social and legal support, throughout the gender transition process for transgender individuals [10, 11]. Transgender populations present specific and unique health-related needs, and the transition process can have substantial psychological and emotional impacts on individuals [7, 12]. It is necessary to identify transgender populations and their unique needs, in order to reach these communities and to provide holistic interventions [13].

In Benin, as in most countries of the African sub-region, transgender people are hidden populations because they fear the social stigmatization that is associated with having a gender identity that does not align with expected sociocultural norms, particularly under legal, political, and media contexts that are less favorable to trans-identities. Although considered priority populations under the broader group of Lesbian, Gay, Bisexual, and Transgender (LGBT) by international actors in the fight against STIs and HIV, and despite the existence of health programs dedicated to LGBT groups, there is limited knowledge around the experience of the transgender population in Benin. In order to reduce this gap and to adapt existing programs to the unique needs of this target group, this work aims to study the transgender experience and the social and community response to trans identities in Benin.

\section{Materials and Methods}

\subsection{Type Study and Study Population}

This was a descriptive cross-sectional study that included individuals who identified and expressed themselves as transgender, were ages 15 years or over, resided in Benin at the time of the study, and provided consent to participate. Hermaphroditic and those who did not consent to participate in the study were excluded.

\subsection{Study Design and Sampling}

Subjects were recruited using respondent-driven sampling. The first persons were selected from facilitators belonging to identity associations. Based on the locations of transgender identity-based organizations, data collection sites were identified and served as priority study areas. After reaching out to various transgender organizations to seek input, seven (07) cities throughout the country were selected for data collection: Natitingou, Parakou, Bohicon,
Ouidah, Porto-Novo, Abomey-Calavi and Cotonou. These cities are spread throughout the country and are fairly representative of the general urban population of Benin.

\subsection{Data Collection: Technique, Tools and Variables}

The data were collected via interview using a structured questionnaire. Four categories of variables were examined: i) sociodemographic variables: Age, sex at birth \& gender identity (Male to Female-MtF or Female to Male-FtM), department of residence, educational level, marital status, religion, employment status; ii) variables relating to the gender transition experience: Age of first identified need for gender transition, Age of readiness for the gender transition, Personal feeling after coming out as trans (Positive / Negative), adaptation of visible changes in dress or physical appearance and/or in behavior (Yes / No), community awareness of transgender identity (Yes / No); iii) variables relating to social reactions: Overall attitude of the community in the face of the transition (Indifference / Acceptance or accompaniment / Rejection or exclusion), Type of living situation (Alone / Family / Partner / Others), Membership in an identity association (Yes / No ), experience of physical and / or verbal aggression (Yes / No), Sought legal action as a result of aggression (Yes / No); Outcomes of action taken, reasons for not taking action; iv) Individual Reactions and Risk Behaviors: Personal Sense of Aggression, Abuse of Alcohol (Yes / No), Use of Tobacco or Drugs (Yes / No), Multi-Sexual Partnership (Yes / No).

\subsection{Data Analysis}

The collected data were captured with EPI DATA software, and were analyzed with the STATA 15 software. Descriptive statistics were calculated, including percentages for the qualitative variables as well as the mean and the standard deviation for the quantitative variables. Comparisons were made with the Student's t-test for mean comparison and the Pearson $\mathrm{Chi}^{2}$ test (or the exact fischer test) for the comparison of proportions. Hypothesis tests were deemed significant at the $5 \%$ level.

\subsection{Ethical Considerations}

Study protocol was validated by the National Committee of Ethics for Health Research. Emphasis was placed on obtaining prior consent from parents and minors before conducting the interviews. The survey was anonymous and confidential, and participation in the study was strictly voluntary. Data from the interviews and survey have been stored securely, maintaining the confidentiality and anonymity of participants. 


\section{Results}

\subsection{Sociodemographic Characteristics}

Table 1. Sociodemographic characteristics of transgenders individuals, Benin, 2017

\begin{tabular}{|c|c|c|}
\hline Variables & $\mathrm{n}$ & $\%$ \\
\hline Age (years) & 326 & \\
\hline Under 20 & 67 & 19.76 \\
\hline 20 to 30 & 233 & 68.74 \\
\hline 30 and older & 41 & 12.09 \\
\hline Sex at birth/Gender & 339 & \\
\hline Male/Male to Female & 305 & 89.97 \\
\hline Female/Female to male & 34 & 10.03 \\
\hline Educational level & 325 & \\
\hline No education & 3 & 0.92 \\
\hline Literate & 1 & 0.31 \\
\hline Primary school & 30 & 9.23 \\
\hline Middle/High school & 163 & 50.15 \\
\hline University & 121 & 37.23 \\
\hline Marital status & 319 & \\
\hline Married & 37 & 11.60 \\
\hline Single & 272 & 85.27 \\
\hline Divorced/Separated & 10 & 3.13 \\
\hline Religion & 324 & \\
\hline Traditional religion & 28 & 8.64 \\
\hline Christian & 219 & 67.59 \\
\hline Muslim & 50 & 15.43 \\
\hline No religion & 14 & 4.32 \\
\hline Other & 13 & 4.01 \\
\hline Nationality & 325 & \\
\hline Beninese & 305 & $93.85 \%$ \\
\hline
\end{tabular}

A total of 326 participants were surveyed. The majority were male at birth, and were transitioning or had transitioned from male to female $\mathrm{MtF}$, (89.57\%). The mean age was $24.13( \pm 4.88)$ and there was no statistically significant difference in age between $\mathrm{MtF}(24.07 \pm 4.79$ years) and FtM (at $24.71 \pm 5.65)$ participants ( $\mathrm{p}=.08738$ ). The Littoral, Atlantic and Ouémé departments accounted for $37.73 \%, 24.54 \%$ and $13.19 \%$ respectively, of participants. The departments of Mono and Couffo had the lowest proportions, $1.23 \%$ and $1.53 \%$ respectively, of the surveyed population. Regarding employment status, $36.50 \%$ of study participants were students, $14.74 \%$ were hotel or restaurant employees, and $3.99 \%$ were unemployed. In addition, participants were primarily Beninese nationals (93.85\%) who were under 30 (88.5\%), single (84.4\%), and with a minimum level of education equivalent to secondary education (87.38\%) (Table 1$)$.

\subsection{Individual Management of Social Affirmation of Transgender Status}

The first indications of desire for gender transition occurred at a significantly earlier age among FtM than among $\operatorname{MtF}(p=0.0001)$, as did the age of readiness for the gender transition $(p=0.001)$. Generally, MtF began wanting to transition after age 16, whereas FtM individuals tended to have such feelings prior to age 15 . In addition, the proportion of transgender individuals who expressed that their transition process was a positive experience, along with those who adopted physical changes to their appearance was significantly higher among FtM as compared to $\mathrm{MtF}(\mathrm{p}<0.05)$. Of the surveyed participants, 211 or about 6 in 10 had informed at least one person in their community about their transition and there was no difference by gender (Table 2). Participants reported that those they were most likely to inform of their gender identity and transition were people outside of their family or their spouse (67.49\% of participants, $n=203$ ).

Table 2. Gender and individual management of social affirmation of transgender status, Benin, 2017

\begin{tabular}{|c|c|c|c|c|c|}
\hline & $\mathrm{n}$ & Male to Female & $\mathrm{n}$ & Female to Male & p-value \\
\hline Average age of first desire for transition & 291 & 12.39 (3.39) & 34 & $10.18(3.46)$ & 0.0001 \\
\hline Average age of readiness for gender transition & & $16.20(3.12)$ & & $14.82(4.14)$ & 0.001 \\
\hline Personal feeling after coming out as trans & 268 & & 30 & & \\
\hline Positive & & $32.09 \%$ & & $56.67 \%$ & 0.007 \\
\hline Changes to physical appearance & 291 & & 34 & & \\
\hline Yes & & $53.95 \%$ & & $79.41 \%$ & 0.005 \\
\hline Community and family aware of transgender status & 291 & & 34 & & \\
\hline Yes & & $64.60 \%$ & & $67.65 \%$ & 0.725 \\
\hline
\end{tabular}




\subsection{Social Reactions Face to Transgender People}

Responses and reactions from the community toward transgender individuals were not directed at any particular trans identity (MtF vs. FtM received similar social reactions). The majority of participants live with family members, with a significantly higher proportion of FtM (70.59\%) living with family as compared to $\mathrm{MtF}$ (65.75\%) $(\mathrm{p}=0.008)$. In addition, 183 subjects, or 56.31\% $(\mathrm{n}=325)$, experienced at least one verbal or physical assault (Table 3). The type of aggression that participants most frequently were subject to was humiliation $(59.02 \%, \mathrm{n}=183)$; other common forms of aggression that participants described receiving were discrimination (48.63\% of cases) and stigmatization (49.18\% of cases). Of the participants who were assaulted, $51 \%$ did not seek legal action against their perpetrators, while $24.57 \%$ and $21.14 \%$ of assault cases asked for help from family or from identity-based organizations, respectively. Security forces were called in $2.86 \%$ of the cases $(n=175)$. The main reasons for the limited use of legal avenues to seek protection or justice include negative perceptions and stigma for transgender populations, as well as the nonexistence or lack of awareness of legal processes among $35.71 \%$ of cases.

Table 3. Social reactions to transgender people, Benin, 2017

\begin{tabular}{|c|c|c|c|c|c|}
\hline & $\mathrm{n}$ & Male to Female & $\mathrm{n}$ & Female to Male & $\mathrm{p}$-value \\
\hline Type of housing & 292 & & 34 & & $0.015 *$ \\
\hline Alone & & $25.00 \%$ & & $14.71 \%$ & \\
\hline With Family & & $65.75 \%$ & & $70.59 \%$ & \\
\hline With sexual partner & & $3.42 \%$ & & $14.71 \%$ & \\
\hline Other & & $5.82 \%$ & & $0.00 \%$ & \\
\hline $\begin{array}{l}\text { Membership in an identity-based } \\
\text { organization }\end{array}$ & 291 & & 34 & & 0.791 \\
\hline Oui & & $75.60 \%$ & & $73.53 \%$ & \\
\hline $\begin{array}{l}\text { Attitudes among community, toward } \\
\text { gender transition }\end{array}$ & 185 & & 23 & & \\
\hline Indifference & & $10.81 \%$ & & $4.35 \%$ & $0.573 *$ \\
\hline Acceptance & & 65.41 & & $78.26 \%$ & \\
\hline Rejection/Exclusion & & 23.78 & & $17.39 \%$ & \\
\hline Assault & 291 & & 34 & & $0.159 *$ \\
\hline Yes & & $54.98 \%$ & & $67.65 \%$ & \\
\hline
\end{tabular}

*Fischer exact test

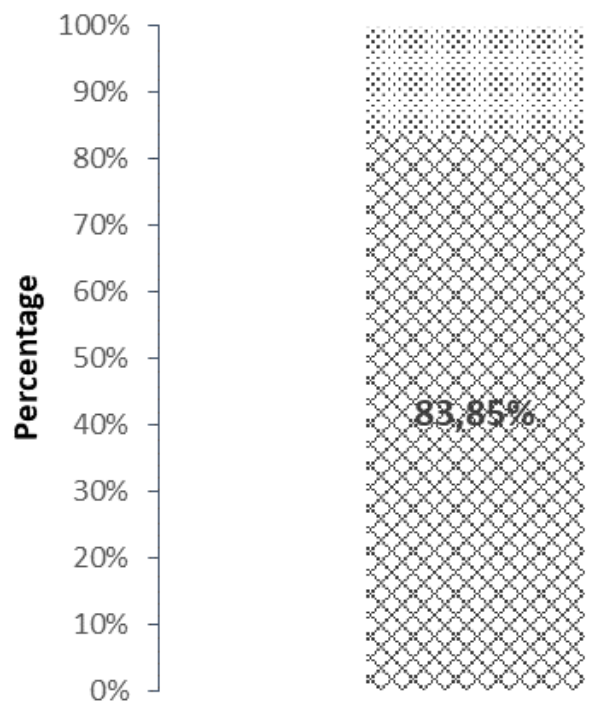

Male to Female

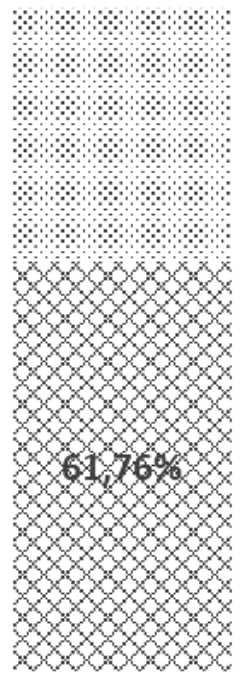

Female to Male

\section{$\$$ Yes No}

Figure 1. Prevalence of sexual multipartnership among transgender people, Benin, 2017 


\subsection{Risk Behaviors in Transgender People}

Having multiple sexual partners is prevalent in at least 6 out of 10 transgender individuals with a significantly higher proportion ( $\mathrm{p}=0.002)$ in $\mathrm{MtF}$ (Figure 1). In addition, alcohol abuse and use of tobacco and / or drugs are prevalent in higher proportions among FtMs respectively in proportions of ( $30 \%$ and $21.88 \%$ respectively) as to their use among $\mathrm{MtF}$ (compared to $20.76 \%$ and $15.28 \%$ ) among MtF. These observed differences, however, are not statistically significant.

\section{Discussion}

This study provides an exploratory view of the transgender population in Benin, with a focus on the identity transition period and related responses by the community and society. This research has helped to identify the characteristics and experiences of the transgender population in Benin, and has demonstrated that it is predominantly young and male. Transgender individuals generally initiate their gender identity transition during childhood, and they inform those outside their immediate circles. Assaults are common among transgender people, causing them to feel humiliated. Few pursued legal recourse after an assault, due to nonexistence or lack of awareness of legal options, along with fear of negative perceptions in the community. The subsequent risk behaviors that occur in response to the stigma and discrimination transgender populations face mainly involve having multiple sexual partners.

\subsection{Strengths and Limitations of the Study}

The respondent-driven sampling method is very commonly used in studies of hidden populations. Thus it was quite appropriate for this study and allowed us to have a more accurate count of transgender individuals in Benin. This research is the first scientific initiative in this field. The precautions taken during collection to guarantee respondents' anonymity can ensure a certain reliability in the quality of information collected and limit information bias. The choice of collection points that are distributed throughout the country guarantees that data are nationally representative. However, as the collection primarily occurred in large cities and existing identity-based organizations, the results may not be generalizable to the overall population of transgender people in Benin. Given the specificity of the population selected for the study and the difficulties in reaching this population, the results nevertheless provide useful data for decision-making and strategic planning in the future.

\subsection{Discussion of Key Differences with Other Studies}

The socio-demographic profile corresponds to that reported in 3 West African countries by Stahlman et al in their study in Côte d'Ivoire, Burkina Faso and Togo on MtF transgender between 2012 and 2015 with a predominance of young subjects (mostly students) ages 20 to 27, all of whom had a relatively high level of education (at the high school and university level) [14]. This profile could be explained by evolution of social perceptions on transgenderism; evolution related to educational level. Thus, higher educational levels would be associated with earlier acceptance and affirmation of transgender identity. These figures are different from results of the studies in Spain and Japan that report older subjects (average around 30 years) with a variation by gender identity. Differences in the results of this study can be explained by the methodological differences related to the sampling. Indeed, for the studies in Spain and Japan, recruitment was voluntary, and research was conducted in a specific context (both were conducted in psychiatric hospitals, since transgender status was long considered a psychiatric pathology) [15, 16]. In our study, there is the possibility of selection bias (due to the sampling methods used), which may explain the under-representation of slightly older transgender people. Such groups likely come from wealthier social classes who are not integrated into the network of identity-based organizations, for fear of social stigma.

According to the results of this study, the management of the identity transition and the coming out process occur at an earlier age and is more easily accepted by the FtM than by the MtF. FtM were on average younger at the first signs of expressing a desire to undergo gender transition and during the initial point of readiness for the gender transition. The proportions of transgender people who report a positive feeling about the transition and of those who have adopted a physical adaptation in relation to their gender are significantly higher among the FtM population compared to MtF. The earlier onset of transition for FtM could be explained by general sex-related personality differences [17]. Positive feelings about coming out and physical adaptation of gender identity could be explained by higher levels of resilience among FtM. On the other hand, it must be recognized that in the Beninese context, a physical adaptation from male to female would be much more difficult for society to accept than the reverse. Family and social support remain imperative and serve as protective factors against mental disorders in transgender youth [11, 18]. In this study, immediate circle attitudes toward transgender people seem to be positive, with more than 7 out of 10 transgender individuals reporting an acceptance or a support by their social networks/communities in their transition. This is confirmed by the fact that a similar proportion of transgender individuals lives with their family. These figures are slightly weaker than those reported by Wilson et al in their study in the United States, which evoke a proportion of $81.5 \%$ of transgender subjects still living with their families [1]. This difference is certainly related to the context and can be explained by a 
greater general acceptance of transgender status in the U.S., as compared to African societies where transgender status can still appear as a myth. The importance of family support in this study can be explained by the young age of the participants and the fact that in African societies, family support is still very present in situations considered pathological (especially when other healthcare is not accessible), transgender identity being still perceived as a psychological disorder. Nevertheless, discrimination and stigmatization remain very frequent (around 50\%) among this population with about 6 out of 10 transgender people being assaulted. These figures are similar to those reported by Wilson et al. who mention $45.9 \%$ of transgender individuals in their sample being subject to discrimination [1]. These situations continue because of the persistence of negative perceptions of LGBT communities, as shown by Abaver et al in South Africa, where less than 5\% of their sample stated that they are against violence against LGBT people [19]. These figures remain alarming because discrimination, violence and stigmatization cause emotional instability, including mental and psychological disorders, and they promote risky behaviors such as those that promote the spread of HIV $[5,14,19]$. In the Beninese context, which is generally characterized by a fatalistic view toward the state's response to violence and discrimination, this state of affairs is perpetuated, and the government's actions remain insufficient. Benin's legislation does not expressly recognize gender identity or provide human rights protections to gender and sexual minorities. However, there is a relative amount of socio-cultural acceptance of gender and sexual minorities as long as their presence does not interfere with public tranquility and is not considered indecent (Code of Criminal Procedure). Nevertheless transgender people are victims of violence of all kinds (verbal, sexual, physical, pyschological, social ...). Less than half of assaulted transgender individuals had opportunity to seek legal action in response, and the security forces were the least sought-after source of assistance. This can be explained by the fear of negative perceptions or violence, even by the police, as well as by the limited awareness of legal protections and structures guaranteeing human rights [20].

In terms of risk behaviors, this study identified multiple sexual partners, along with alcohol abuse and use of tobacco and other substances, with such behaviors occurring predominantly among MtF. Adolescents and young adults in general are already more inclined to adopt certain risk behaviors because of the physiological and physical changes inherent in this stage of human development, and this is more pronounced for transgender people [21]. The proportion of participants who abuse alcohol and drugs was lower in our study. According to Budhwani et al, 26\% of transgender people in the Dominican Republic reported using illegal drugs; Peacock et al cite a proportion of $61 \%$ of alcohol misuse in El Salvador [22, 23]. The presence of multiple sexual partners is frequent in our sample and particularly in the MtF: more than 8 out of 10 reported multiple sexual partners. Chen et al in their study in China evoke a proportion of $56 \%$ of transgender individuals with occasional partners [24]. The differences can be explained on the one hand by methodological factors, for example regarding the definition of the abuse of alcohol, and on the other hand in the context of Benin, by a lower consumption of alcohol in the general population [25]. A social desirability bias cannot be totally excluded in the context, although it is unlikely to have occurred in this survey.

Although the figures reported in this study differ from those reported in the literature, there is agreement that these risky behaviors provide an outlet for stressors as a result of the stigma and discrimination that transgender individuals face, and that such behaviors strongly contribute to the transmission of HIV in this population, putting them at greater risk than Men who have Sex with Men [6, 22, 23].

\section{Conclusions}

This study confirmed that transgender populations exist in Benin. It confirms the social difficulties that these populations may face and also their place in the persistence of HIV transmission. The findings from this research must be taken into account in a holistic vision to develop strategies adapted to the unique needs of transgender individuals in Benin, in order to contribute to the reduction of HIV incidence in the country.

\section{Acknowledgements}

We are sincerely grateful to Plan International Benin for funding data collection.

\section{Competing Interests}

The authors declare that they have no competing interests.

\section{REFERENCES}

[1] Wilson EC, Chen Y-H, Arayasirikul S, Raymond HF, McFarland $\mathrm{W}$. The Impact of Discrimination on the Mental Health of Trans*Female Youth and the Protective Effect of Parental Support. AIDS and behavior. 2016; 20: 2203-11.

[2] Mueller SC, De Cuypere G, T'Sjoen G. Transgender Research in the 21st Century: A Selective Critical Review from a Neurocognitive Perspective. Am J Psychiatry. 2017; 174: $1155-62$.

[3] Reisner SL, Poteat T, Keatley J, Cabral M, Mothopeng T, Dunham E, et al. Global health burden and needs of transgender populations: a review. Lancet. 2016; 388: 
412-36.

[4] Lyons C, Stahlman S, Holland C, Ketende S, Van Lith L, Kochelani D, et al. Stigma and outness about sexual behaviors among cisgender men who have sex with men and transgender women in Eswatini: a latent class analysis. BMC Infect Dis. 2019; 19: 211.

[5] Chakrapani V, Newman PA, Shunmugam M, Logie CH, Samuel M. Syndemics of depression, alcohol use, and victimisation, and their association with HIV-related sexual risk among men who have sex with men and transgender women in India. Glob Public Health. 2017; 12: 250-65.

[6] Poteat T, Ackerman B, Diouf D, Ceesay N, Mothopeng T, Odette KZ, et al. HIV prevalence and behavioral and psychosocial factors among transgender women and cisgender men who have sex with men in 8 African countries: A cross-sectional analysis. PLoS Med. 2017; 14: e1002422.

[7] Poteat T, Scheim A, Xavier J, Reisner S, Baral S. Global Epidemiology of HIV Infection and Related Syndemics Affecting Transgender People. J Acquir Immune Defic Syndr. 2016; 72 Suppl 3:S210-9.

[8] Jobson GA, Theron LB, Kaggwa JK, Kim HJ. Transgender in Africa: invisible, inaccessible, or ignored? Sahara j. 2012; 9: $160-3$.

[9] Evans MG, Cloete A, Zungu N, Simbayi LC. HIV Risk Among Men Who Have Sex With Men, Women Who Have Sex With Women, Lesbian, Gay, Bisexual and Transgender Populations in South Africa: A Mini-Review. Open AIDS J. 2016; 10: 49-64.

[10] Logie CH, Lacombe-Duncan A, Lee-Foon N, Ryan S, Ramsay H. "It's for us -newcomers, LGBTQ persons, and HIV-positive persons. You feel free to be": a qualitative study exploring social support group participation among African and Caribbean lesbian, gay, bisexual and transgender newcomers and refugees in Toronto, Canada. BMC Int Health Hum Rights. 2016; 16: 18.

[11] Johns MM, Beltran O, Armstrong HL, Jayne PE, Barrios LC. Protective Factors among Transgender and Gender Variant Youth: A Systematic Review by Socioecological Level. J Prim Prev. 2018; 39: 263-301.

[12] Jackman K, Honig J, Bockting W. Nonsuicidal self-injury among lesbian, gay, bisexual and transgender populations: an integrative review. J Clin Nurs. 2016; 25: 3438-53.

[13] Delany-Moretlwe S, Cowan FM, Busza J, Bolton-Moore C, Kelley K, Fairlie L. Providing comprehensive health services for young key populations: needs, barriers and gaps. J Int AIDS Soc. 2015; 18: 19833.

[14] Stahlman S, Liestman B, Ketende S, Kouanda S, Ky-Zerbo $\mathrm{O}$, Lougue $\mathrm{M}$, et al. Characterizing the HIV risks and potential pathways to HIV infection among transgender women in Côte d'Ivoire, Togo and Burkina Faso. Journal of the International AIDS Society. 2016; 19: 20774-.

[15] Miyajima E, Taira N, Koda M, Kondo T. Differences in personality traits between male-to-female and female-to-male gender identity disorder subjects. Psychiatry Research. 2014; 220: 496-9.

[16] Gómez-Gil E, Gutiérrez F, Cañizares S, Zubiaurre-Elorza L,
Monràs M, Esteva de Antonio I, et al. Temperament and character in transsexuals. Psychiatry Research. 2013; 210: 969-74.

[17] Bacon AM, Lenton-Maughan L, May J. Trait emotional intelligence and social deviance in males and females. Personality and Individual Differences. 2018; 122: 79-86.

[18] Johnson B, Leibowitz S, Chavez A, Herbert SE. Risk Versus Resiliency: Addressing Depression in Lesbian, Gay, Bisexual, and Transgender Youth. Child and Adolescent Psychiatric Clinics of North America. 2019.

[19] Abaver DT, Cishe EN. Violence, abuse and discrimination: key factors militating against control of HIV/AIDS among the LGBTI sector. Sahara j. 2018; 15: 60-70.

[20] Logie CH, Lacombe-Duncan A, Kenny KS, Levermore K, Jones N, Marshall A, et al. Associations between Police Harassment and HIV Vulnerabilities among Men Who Have Sex with Men and Transgender Women in Jamaica. Health and human rights. 2017; 19: 147-54.

[21] Day JK, Fish JN, Perez-Brumer A, Hatzenbuehler ML, Russell ST. Transgender Youth Substance Use Disparities: Results from a Population-Based Sample. J Adolesc Health. 2017; 61: 729-35.

[22] Budhwani H, Hearld KR, Milner AN, McGlaughlin E, Charow R, Rodriguez-Lauzurique RM, et al. Transgender Women's Drug Use in the Dominican Republic. Transgend Health. 2017; 2: 188-94.

[23] Peacock E, Andrinopoulos K, Hembling J. Binge Drinking among Men Who Have Sex with Men and Transgender Women in San Salvador: Correlates and Sexual Health Implications. J Urban Health. 2015; 92: 701-16.

[24] Chen W, Zhang X, Lyu C, Dong L, Du Y, Fu J. [Gender characteristics and HIV/AIDS related knowledge awareness and behaviors of transgender women]. Zhonghua Liu Xing Bing Xue Za Zhi. 2016; 37: 76-9.

[25] Ministère de la Santé. Rapport final de l'enquête pour la surveillance des facteurs de risque des maladies non transmissibles par l'approche "STEPSwise" de l'OMS ENQUETE "STEPS 2015" au Bénin. Cotonou: Ministère de la Santé; 2016. 